\title{
TRIGONOMETRIA NO TRIÂNGULO RETÂNGULO: AS INTERAÇÕES EM SALA DE AULA SOB A ÓTICA DA TEORIA DAS SITUAÇÕES DIDÁTICAS
}

\author{
L. A. C. REIS ${ }^{1 *}$ e N. S. G. ALLEVATO ${ }^{2}$ \\ ${ }^{1}$ Instituto Federal de Educação, Ciência e Tecnologia de São Paulo \\ ${ }^{2}$ Universidade Cruzeiro do Sul \\ luciano.reis@ifsp.edu.br*
}

Artigo submetido em agosto/2013 e aceito em fevereiro/2015

DOI: $10.15628 /$ holos.2015.1616

\section{RESUMO}

Considerando o desafio de propiciar um ensino de melhor qualidade e uma aprendizagem significativa para os alunos do Ensino Médio, este artigo tem por objetivo descrever e analisar uma prática de ensino de Trigonometria no triângulo retângulo, considerando as interações que ocorrem entre os sujeitos do processo educativo sob a ótica da Teoria das Situações Didáticas, de Guy Brousseau. O estudo, de natureza qualitativa, envolveu alunos de um câmpus do Instituto Federal de Educação, Ciência e Tecnologia do Estado de São Paulo, e os dados foram coletados por observação das atividades em sala de aula e registrados por meio de gravação das falas dos alunos e do professor e de um diário de campo. Este trabalho pretende mostrar a importância de dar voz aos alunos, elencando as estratégias usadas na busca pela construção do conhecimento, baseadas nas interações mediadas pelo professor e pelo diálogo entre as partes. Os resultados mostram que as etapas de devolução, ação, formulação, validação e institucionalização são importantes elementos das situações didáticas e que, através delas, os processos de ensino e aprendizagem contribuem para a construção do conhecimento.

PALAVRAS-CHAVE: Ensino Médio, Teoria das Situações Didáticas, Trigonometria.

\section{TRIGONOMETRY IN TRIANGLE RECTANGLE: INTERACTIONS IN THE CLASSROOM THE PERSPECTIVE OF DIDACTIC THEORY OF SITUATIONS}

\begin{abstract}
Considering the challenge of providing a better quality teaching and meaningful learning for high school students, this article aims to describe the practice of teaching trigonometry in triangle, considering the interactions that occur between the subjects of the educational process in the optical Didactic Theory of Situations, Guy Brousseau. The study was qualitative, involving students of a campus of the Federal Institute of Education, Science and Technology of the State of São Paulo, and the data were collected by observation of activities in the classroom and recorded by recording the
\end{abstract}

speech of students and teacher and a field diary. This paper intends to show the importance of giving voice to students, listing the strategies used in the search for knowledge construction, based on interactions mediated by the teacher and the dialogue between the parties. The results show that steps back, action, formulation, validation and institutionalization are important elements of didactic situations and, through them, the processes of teaching and learning contribute to the construction of knowledge

KEYWORDS: High School, Didactic Theory of Situations, Trigonometry. 


\section{INTRODUÇÃO}

Este artigo é parte de uma pesquisa maior, que pretende compreender como as interações que ocorrem numa sala de aula, num curso de Ensino Médio, favorecem a construção do conhecimento, à luz da Teoria das Situações Didáticas (TSD), de Guy Brousseau (1988, 1996a, 1996b).

Tal pesquisa foi motivada por inquietações emergentes de nossa prática educacional, nos vários anos de magistério com alunos das redes pública e privada, dos Ensinos Fundamental, Médio e Superior, e dos cursos preparatórios para o vestibular.

Acreditamos, como argumento principal para a educação, que os processos de ensino e aprendizagem deveriam basear-se nas interações entre o professor e os alunos, buscando a construção de um conhecimento embasado nas vivências anteriores e na troca de experiência entre ambos. Nossa experiência nos faz crer que, mesmo num ensino propedêutico, como é feito num curso preparatório para o vestibular, tal interação se faz possível e necessária.

O aluno constrói significados a partir de experiências e conhecimentos adquiridos nas múltiplas e complexas interações que trouxe da família, dos grupos nos quais está inserido e das etapas anteriores de sua escolarização se transformando em protagonista do seu processo de aprendizagem. Cabe, ao professor, o papel de mediador nessa interação dos alunos com outros agentes e com os objetos de conhecimento. Diante disto, vimos a necessidade de aprofundar compreensões sobre as formas como as interações em sala de aula contribuem para a construção do conhecimento matemático, no ensino de Matemática, mais especificamente no conteúdo Trigonometria no triângulo retângulo.

Na seção 1 destacamos e discutimos alguns elementos específicos da Teoria das Situações Didáticas (TSD) (os saberes: científico, a ensinar e ensinado; a relação saber/professor/aluno e as interações em sala de aula), a partir das concepções de Brousseau e apoiados nas concepções de alguns pesquisadores que se debruçaram sobre essa teoria.

Na seção 2 trazemos uma discussão sobre alguns recursos que auxiliam os processos de ensino e de aprendizagem, entre eles, o livro didático (material de apoio para o professor e para o aluno), os sites da internet (ferramentas que auxiliam na busca do conhecimento) e o diálogo (elemento de fundamental importância para a construção do conhecimento).

Em seguida, apresentamos, brevemente, a metodologia da pesquisa, relatando, então, momentos de 3 (três) aulas cujo objetivo era apresentar a Trigonometria no triângulo retângulo aos alunos, e verificar o que foi aprendido. A condução desses momentos é relatada evidenciando a forma como os alunos manifestam conhecimentos prévios e como o professor os incita e questiona sobre tais conhecimentos, buscando ajudá-los na construção de novos saberes. Em nossas análises ressaltamos a importância de alguns aspectos presentes na TSD, que nos ajudaram a ampliar as reflexões sobre essas aulas. Encerramos, então, com nossas considerações finais. 


\section{A TEORIA DAS SITUAÇÕES DIDÁTICAS (TSD)}

Até meados de 1986, Piaget $^{1}$, dentre outros, ressaltava a visão cognitivista no campo da Educação. Ele evidenciava o papel central da ação no desenvolvimento do raciocínio, na originalidade do pensamento matemático e nas etapas de seu desenvolvimento nas crianças, mas não considerava a estrutura formal da Matemática e a função da lógica como fundamentais para a construção do conhecimento.

Nesse contexto, Guy Brousseau², se dedicou a um estudo aprofundado, com a finalidade de compreender as condições que levariam um sujeito a usar seus conhecimentos para tomar decisões, e estudar as razões dessa tomada de decisão. Criou, então, a Teoria das Situações Didáticas, um modelo teórico desenvolvido na França, que procurava entender as diferentes condições e a forma como o conhecimento matemático pode ser aprendido pelo aluno. Tal teoria se faz importante pelo fato, entre outros, de abordar aspectos específicos do saber matemático, procurando promover uma educação matemática com mais significado para o aluno. Segundo Freitas (1999, p. 66), "esse significado consiste basicamente em proporcionar ao aluno um conhecimento que esteja realmente vinculado ao processo de sua promoção existencial".

Para o aluno, o significado do saber matemático tem forte influência da forma como o conteúdo lhe é apresentado. A estruturação das atividades de aprendizagem é uma das responsáveis pelo comprometimento do aluno e denomina-se situação didática. Para Brousseau (1996a) uma situação didática é

[...] um conjunto de relações estabelecidas explicitamente ou implicitamente entre um aluno ou um grupo de alunos, num certo meio, compreendendo eventualmente instrumentos e objetos, e um sistema educativo (o professor) com a finalidade de possibilitar a estes alunos um saber constituído ou em vias de constituição. (BROUSSEAU, 1996a, p. 36)

As situações didáticas envolvem uma diversidade de elementos entre os quais destaco: contrato didático, obstáculos epistemológicos, dialética ferramenta-objeto, transposição didática entre outras. O contrato didático, por exemplo, que ganhará destaque neste trabalho, é um conjunto de obrigações implícitas ou explícitas relativas a um saber entreposto entre o professor e os alunos.

Para Freitas (1999, p. 67), "através da análise das situações didáticas é possível investigar toda a problemática da aprendizagem matemática e desvelar aspectos que ocorrem durante a resolução de problemas e a elaboração de conceitos pelos alunos". Assim, na situação didática são identificadas as interações entre o saber, o professor e o aluno.

\footnotetext{
1 Jean Piaget era um pensador suíço, autor da conhecida concepção construtivista da formação da inteligência, denominada Teoria de Epistemologia Genética ou Teoria Psicogenética, que explicava como o indivíduo, desde o seu nascimento, constrói o conhecimento.

${ }^{2}$ Guy Brousseau, um dos pioneiros da Didática da Matemática Francesa, é professor aposentado do IUFM (Instituto Universitário de Formação de Professores), em Aquitaine e da Universidade Bordeaux 1, situados na França. Ele ganhou A 'Felix Klein Medal' da Educação Matemática em 2003, da International Commission on Mathematical Instruction (ICMI), em reconhecimento à contribuição que tem proporcionado ao desenvolvimento da educação matemática como um campo de investigação científica, no campo teórico, estendendo suas investigações a estudantes e professores.
} 
Desse modo, na próxima subseção fazemos um estudo sobre os tipos de saberes, elencando e explicitando suas diferenças; e na subseção seguinte, desenvolvemos reflexões e discussões sobre a tríade saber/professor/aluno.

\subsection{Os saberes: científico, a ensinar e ensinado}

No que se refere à construção do conhecimento, mais especificamente no ensino da Matemática, Brousseau (1988) estabelece as diferenças entre saber e conhecimento. Para ele, o saber está associado ao problema da validação do conhecimento que, na Matemática, se refere ao raciocínio lógico-dedutivo. O conhecimento, por outro lado, está vinculado ao aspecto experimental e envolve algum tipo de ação com a qual o sujeito tenha um contato mais pessoal.

Nesse sentido, Pais (2008) afirma:

Na linguagem usada no meio científico, o saber é quase sempre caracterizado por ser relativamente descontextualizado, despersonalizado e mais associado a um contexto científico histórico e cultural. Assim, por exemplo, quando se fala em saber matemático se refere a uma ciência que tem sua concepção estruturada num contexto próprio. Por outro lado, o conhecimento sempre diz respeito ao contexto mais individual e subjetivo, revelando algum aspecto com o qual o sujeito tem uma experiência direta e pessoal. Nessa concepção o conhecimento está mais associado a um caráter experimental. (PAIS, 2008, p. 14).

No processo da construção do conhecimento, os saberes têm um importante papel. É através dos saberes que os processos de ensino e aprendizagem se concretizam. Nesse contexto, Pais $(2008$, p. 21) ressalta três saberes que compõem tal processo: o saber científico, o saber a ensinar e o saber ensinado.

O saber científico se relaciona à vida acadêmica, embora acredita-se que nem tudo que se produz academicamente represente um saber científico. Tal saber está mais vinculado e é desenvolvido nas universidades ou nos institutos de pesquisa, e não está diretamente ligado ao Ensino Médio e Fundamental. Vincula-se a áreas como a economia, a política e a tecnologia. Sobre esses vínculos, Pais (2008, p. 22) afirma que "na sociedade, o saber científico e, sobretudo, a tecnologia estabeleceram laços de profundas ligações mútuas, a ponto de todo o conforto do mundo contemporâneo estar submetido a esse comprometimento".

Belo (2004) afirma que o saber científico "é o conhecimento racional, sistemático, exato e verificável da realidade. Sua origem está nos procedimentos de verificação baseados na metodologia científica".

No que tange ao aspecto educativo, é evidente que o saber científico deveria contribuir, também, para o desenvolvimento crítico do educando, priorizando os valores éticos da educação. Pais (2008) sinaliza que

[...] apesar de não parecer evidente que o saber científico não pode ser ensinado nos textos técnicos, essa questão se constitui num obstáculo que deve ser considerado no processo de aprendizagem. Essa é a questão da formalização precipitada da linguagem científica. (PAIS, 2008, p. 23). 
Parece claro que o saber científico não pode ser ensinado na forma que se encontra redigido nos textos técnicos. A finalidade educacional desse saber científico deve estar voltada para questões mais essenciais do plano social. Se faz necessário, então, um trabalho didático que vise a prática educativa, procedendo uma reformulação na mesma e viabilizando a passagem do saber científico para o saber escolar. É necessário recorrer à elaboração de uma forma didática; destaca-se, então, a importância de uma metodologa fundamentada numa proposta pedagógica.

Tal proposta pedagógica nos remete ao saber a ensinar ou saber a ser ensinado. Nesse saber existe uma gama de aspectos cuja análise é essencial à questão educacional. Este saber está ligado a uma forma didática que serve para apresentar, ao aluno, o saber. É necessária, então, uma mudança considerável, não só no conteúdo em si como também nos objetivos de sua utilização. Pais $(2008$, p. 24) afirma que "na passagem do saber científico ao saber a ser ensinado ocorre a criação de um verdadeiro modelo teórico que ultrapassa os próprios limites do saber matemático".

Enquanto o saber científico é apresentado à comunidade científica através de artigos, teses, livros especializados e relatórios, o saber a ensinar limita-se quase sempre aos livros didáticos, programas e outros materiais de apoio. Tais materiais surgem, então, para fornecer o essencial da intenção de ensino, fincados em teorias didáticas cuja finalidade está voltada ao trabalho do professor.

Esse processo da didática é fortemente influenciado por elementos internos e externos ao ambiente educacional. Esses elementos são compostos de diferentes conjuntos de regras, representados, por exemplo, pela força do mercado (livros didáticos e/ou paradidáticos); pelas forças políticas (programas e currículos de secretarias de Educação); pelas forças institucionais da pesquisa e pela própria instituição escolar (tipo de escola, objetivos, projeto pedagógico).

Também, em função da diversidade dos gêneros discursivos e dos interlocutores, há uma transformação de saberes que ocorre nas diferentes práticas sociais. Sobre isso, Polidoro e Stigar (2010) afirmam que

[...] esse processo de transformação do saber se dá porque os funcionamentos didático e científico não são os mesmos. Eles se inter-relacionam, mas não se sobrepõem. Assim, para que um determinado saber seja ensinado, em situação acadêmico-científica ou escolar, necessita passar por transformação, uma vez que não foi criado com o objetivo primeiro de ser ensinado. (POLIDORO \& STIGAR, 2010, p. 155)

Assim, o trabalho do professor envolve mais uma simulação de descoberta do saber, e o saber acadêmico se vincula à descoberta da ciência.

O saber a ensinar, segundo Almouloud (2011, p. 197), "é o que o professor acha que deve ensinar a partir da leitura de livros didáticos, do livro do professor, ou a partir de práticas tidas anteriormente. O texto do saber a ensinar não está completamente escrito em lugar algum".

O processo do ensino resulta, então, no saber ensinado que é aquele que o professor registra no seu plano de aula e que, não necessariamente, coincide com a intenção prevista nos objetivos programados no nível do saber a ensinar. Geralmente, é nesse nível do saber que o professor intervém. 
É certo que não há garantias de que o resultado da aprendizagem corresponda exatamente ao saber ensinado. Deve-se atentar para o fato de que o saber ensinado, na prática educativa, não pode ser concebido como uma simplificação do saber científico. Desse modo, pode-se chegar a informações bem distantes do saber científico e que, nos casos extremos, permanecem apenas alguns vestígios do significado principal.

Segundo Chevallard (1991, p. 110), "para chegar à escola o saber científico sofre transformações que o simplificam a fim de convertê-lo em objeto de estudo escolar". É preciso evitar que, ao simplificá-lo, perca-se o foco do conteúdo, incidindo em erros conceituais e informações incorretas. De fato, teorias complexas, sem perder suas propriedades e características, precisam ser transformadas para serem assimiladas pelos alunos.

Se, de um lado, há uma metodologia científica, com toda a sua especificidade, do outro, há uma metodologia de ensino, essencialmente diferente e conduzida pelos objetivos educacionais. Tal metodologia tem sentido quando se propõe a relacionar saber, professor e aluno o que retrataremos na próxima subseção.

\subsection{A relação saber/professor/aluno}

Com o propósito de modelar a TSD, Brousseau (1988) propôs o triângulo didático (Figura 1), que comporta três elementos: o saber, o professor e o aluno. Tais elementos são as partes que constituem uma relação dinâmica e complexa - a relação didática. A relação didática leva em consideração as interações entre professor e alunos, mediadas pelo saber.

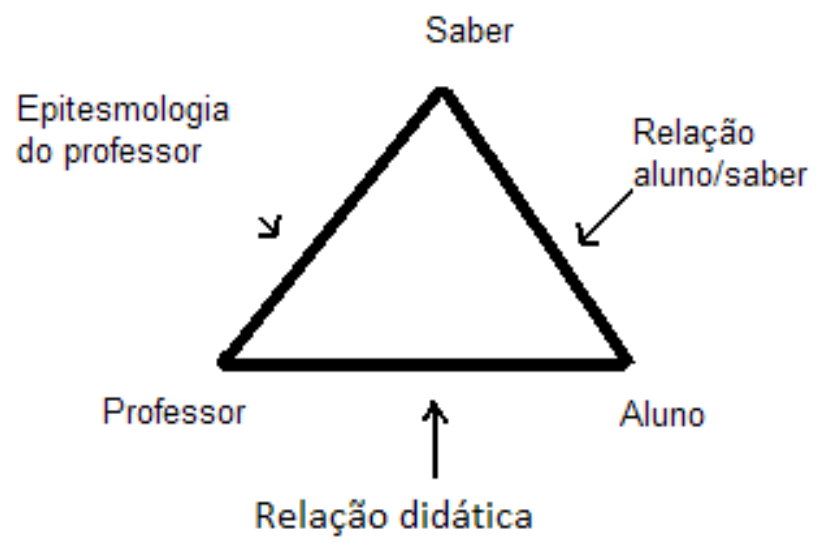

Figura 1: O Triângulo Didático, criado por Brousseau.

Fonte - Brousseau, 1988, p. 320

Segundo Menezes, Lessa e Menezes $\left(2006^{3}\right.$ ), em relação ao saber, o professor e o aluno têm uma relação assimétrica. Espera-se, então, que a relação didática possibilite uma mudança na posição do aluno frente ao saber. Através de situações de ensino propícias, cabe ao professor o papel de incitar o aluno na busca por novos saberes.

Para aprender, o aluno deve assumir um papel ativo diante de uma situação, comparado ao ato de produzir de um matemático. Nesse sentido Brousseau (1996 b) afirma que "a resposta inicial que o aluno pensa frente à pergunta formulada não [deve ser] a que desejamos ensinar-

\footnotetext{
${ }^{3}$ Os documentos que não apresentam numeração de página foram localizados nos sites da internet.
} 
Ihe: se fosse necessário possuir o conhecimento a ser ensinado para poder responder, não se trataria de uma situação de aprendizagem." (BROUSSEAU, 1996b, p. 49)

Desse modo, quando o aluno alicerça sua resposta em conhecimentos anteriores, ocorre um desequilíbrio que o impulsiona a buscar mudanças na estratégia inicial, acomodando seu sistema de conhecimentos. Tais mudanças provocadas pela situação didática serão, então, o motor de sua aprendizagem.

Há um avanço, em relação à aprendizagem, quando o aluno se encontra numa situação didática em que é incitado a explicar seus métodos e procedimentos para a resolução de um problema. Segundo Echeita e Martin (1995, p. 15), "para o aluno que assume o papel social de explicar, o avanço cognitivo provém do fato de ter que organizar seu pensamento para dar as instruções apropriadas".

Entende-se, então, que os processos de ensino e de aprendizagem são fortemente condicionados pelo perfil e pela forma de atuar, tanto do aluno como do professor. Para que o aluno transforme o saber em conhecimento, é necessário que o professor providencie situações que Ihe sejam favoráveis. Segundo Brousseau (1996b), para viabilizar tal situação, o professor deve fazer um duplo papel cíclico:

- procurar situações que possibilitem, aos alunos, dar sentido ao conhecimento, através da contextualização e personalização do saber, num movimento de vivenciar o conhecimento pelo aluno.

- ajudar seus alunos, de forma inversa, despersonalizando e descontextualizando os conhecimentos, do mesmo modo como fazem os matemáticos, de modo a tornar as produções dos alunos fatos universais e reutilizáveis.

Se torna necessário, então, que o professor crie situações didáticas favoráveis se valendo das interações em sala de aula para efetivar a construção do conhecimento matemático.

\subsection{As interações em sala de aula: situações didáticas e a-didáticas}

Na busca pela construção do conhecimento, no dia a dia, acontecem, em sala de aula, interações entre os alunos e o professor e entre os alunos. Para que a aprendizagem seja concretizada, nesse processo interativo, o professor precisa ser o mediador e os alunos, protagonistas na construção do próprio conhecimento.

Em linhas gerais, o professor terá como trabalho inicial "propor ao aluno uma situação de aprendizagem para que [este] elabore seus conhecimentos como resposta pessoal a uma pergunta, e os faça funcionar ou os modifique como resposta às exigências do meio e não a um desejo do professor" (BROUSSEAU, 1996b, p. 49)

Ressalto que um dos fatores apontados por Brousseau (1988) quando evidencia a necessidade de planejamento para a situação didática é evitar que os alunos rapidamente identifiquem a situação com seu contexto matemático, que poderia ocasionar desgaste da situação didática e prejuízo à construção do conhecimento.

Propõe-se, então, por esse modelo, que se rompa com o padrão de aula onde todos os papéis estão bem definidos, com o professor sendo o tutor da didática e do ato de ensinar e o aluno seja o sujeito passivo da aprendizagem proposta pelo professor. 
Numa situação didática, o papel do conhecimento é permitir a antecipação (o aluno aplica suas estratégias na busca das soluções), e o papel do professor dar autonomia ao aluno para que ele atue sobre a situação, sem interferência explícita, nem condução. Para Brousseau (1996b, p. 54), "se uma situação leva o aluno à solução como um trem em seus trilhos, qual é a sua liberdade de construir seu conhecimento? Nenhuma".

Embora a didática tenha o papel de oferecer um conjunto de situações de ensino, na busca pelo aperfeiçoamento das aulas, é importante ressaltar, segundo Brousseau (1988), que nem sempre é necessária a elaboração de situações didáticas para um determinado assunto. As situações didáticas são, muitas vezes, sedimentadas num sistema antagonista, sem intenção didática explícita e exterior ao aluno, abrangendo as situações-problema, os jogos, os conhecimentos dos colegas e do professor. Tal sistema indica o meio a-didático, que Brousseau denomina 'milieu'.

O 'milieu' deve possibilitar a interação autônoma do aluno em relação às situações em que interage e em relação ao professor. Essa ideia indica que o 'milieu'deve ser organizado para que a aprendizagem seja feita de interações, desequilíbrios, assimilações e acomodações. Desta forma, o aluno pode refletir sobre seu 'fazer e desfazer', impondo restrições através de regras que devem ser respeitadas.

É sabido que o aluno é um ser dotado de experiências anteriores adquiridas em sua trajetória escolar, no convívio com a família e com os grupos sociais nos quais ele está inserido. Chevallard (1991) afirma que um novo conhecimento se constrói a partir de conhecimentos antigos e, também, contra esses. Isto permite a constituição de saberes matemáticos, através da mobilização de outros conhecimentos como ferramentas.

Deste modo, o educando se adapta a um contexto onde ocorre um conjunto "de contradições, de dificuldades, de desequilíbrios, um pouco como faz a sociedade humana. Este saber, fruto da adaptação do aluno, manifesta-se através de respostas novas, que são a prova da aprendizagem" (BROUSSEAU, 1996a, p. 49).

Segundo os PCNEM (BRASIL, 2000),

[...] todo conhecimento é socialmente comprometido e não há conhecimento que possa ser aprendido e recriado se não se parte das preocupações que as pessoas detêm. O distanciamento entre os conteúdos programáticos e a experiência dos alunos certamente responde pelo desinteresse e até mesmo pela deserção que constatamos em nossas escolas. [...] A aprendizagem significativa pressupõe a existência de um referencial que permita aos alunos identificar e se identificar com as questões propostas.[...] toda aprendizagem significativa implica uma relação sujeito-objeto e para que esta se concretize, é necessário oferecer as condições para que os dois pólos do processo interajam. (BRASIL, 2000, p. 22)

O papel do conhecimento que os alunos já possuem no momento de resolver uma situação didática é poder encaminhar (ou não) à resolução de um problema - aliás, é para validar ou refutar as ideias deles que as situações didáticas são propostas. Inicialmente, cada um dá um passo utilizando o que sabe para formular hipóteses de resolução do problema. Quando não dá certo, o estudante elimina os conhecimentos inadequados para aquela situação e começa a pensar em outras possibilidades. Gálvez (1996) observa que está incluso o estudo de situações 
que sejam exitosas ou fracassadas, pois o erro constitui fonte de informação para a elaboração de boas questões ou situações-problema.

Para Brousseau (1996a), o erro é um conhecimento que, até certo ponto, conduz ao acerto, porém, a partir de determinado momento se torna falho, ou simplesmente inadaptável. 0 erro é considerado necessário para desencadear o processo de aprendizagem do aluno.

É importante ressaltar a valorização do erro para a construção do conhecimento. O erro leva o educando a pensar, a reformular, a discutir e a dialogar. Tais ações dos alunos manifestamse em algumas etapas que se estabelecem nas relações de ensino e aprendizagem. Nessas relações aparecem, também, outras regras que funcionam como cláusulas de um contrato.

O conjunto das cláusulas que estabelecem essas regras é chamado contrato didático, o qual reflete e organiza as formas de interação em sala de aula. Para Brousseau (1996a),

[...] chama-se contrato didático o conjunto de comportamentos do professor que são esperados pelos alunos e o conjunto de comportamentos dos alunos que são esperados pelo professor. [...] Esse contrato é o conjunto de regras que determinam uma pequena parte explicitamente, mas sobretudo implicitamente, do que cada parceiro da relação didática deverá gerir e daquilo que, de uma maneira ou de outra, ele terá de prestar conta perante o outro. (BROUSSEAU, 1996a, p. 38)

Alguns elementos são de fundamental importância para que o contrato didático cumpra o papel de organizar as relações do saber, do professor e do aluno. As estratégias de ensino, as escolhas pedagógicas, os objetivos do curso e as condições de avaliação são alguns destes elementos. É preciso estabelecer que tipo de relação didática se quer construir:

[...] se a relação didática desenvolve-se num ambiente em que o professor dá aulas expositivas, em que predominam as definições, os exemplos e as listas de exercícios para os alunos resolverem, aí o conjunto de regras, explícitas ou implícitas, que regem o gerenciamento da atividade será muito diferente daquele que direciona uma prática pedagógica em que os alunos trabalham realizando atividades propostas e, no final, o professor, em uma sessão coletiva, procura institucionalizar o conceito trabalhado e propõe exercícios de fixação e/ou verificação do aprendizado. (SILVA, 2008, p. 51)

É muito comum, em Matemática, a prática pedagógica em que o professor cumpre seu contrato ministrando aulas expositivas e remetendo exercícios aos educandos e, estes, cumprem seu contrato, compreendendo ou não a aula e conseguindo resolver, corretamente ou não, os exercícios.

O contrato didático se torna diferente quando o professor propõe uma estratégia de ensino focada num trabalho individual ou em duplas, seguindo roteiros e regras préestabelecidas por ele, e institucionaliza o saber através de sessões coletivas. Para Silva (2008, p. 53), nesse contexto "o professor apoia-se nas produções pessoais ou coletivas dos alunos (resultados de atividades propostas através de um problema) para fazer progredir o aprendizado de toda classe".

Na verdade, a participação e a colaboração, do aluno e do professor, na construção e no pacto do contrato didático são fundamentais para que ações deste processo sejam cumpridas 
continuamente de forma bilateral e atinjam suas expectativas. Quanto a isso, Chaves (2013, p. 6) sinaliza que "embora no contrato didático não exista um documento formalmente assinado pelo professor e pelos alunos, não significa que ambos não tenham expectativas contratuais um para os outros, e vice-versa".

O contrato didático é, portanto, o regulador das intenções do aluno e do professor diante da situação didática. Aluno e professor aceitam o contrato didático quando o primeiro se mobiliza a enfrentar o problema e o segundo se conscientiza que não deve intervir na transmissão explícita de conhecimentos.

Entretanto, embora na maior parte das relações, em sala de aula, exista uma vontade de ambos os atores em cumprir fielmente tal contrato didático, às vezes, tal acordo se rompe. Para Silva, em muitos casos, é preciso que

[...] haja a ruptura e a renegociação do mesmo para o avanço do aprendizado. Um exemplo bastante elucidativo de ruptura do contrato didático, nessa situação, é o caso em que o professor pretende introduzir um conceito novo através, não de uma aula expositiva (definição, propriedades, exemplos, lista de exercícios), mas por meio de atividades em que os alunos resolvem questões trabalhando individualmente ou em dupla e estes, quando devem trabalhar, reagem através de questões do tipo "não sei fazer", "como começa?", "a teoria não foi dada", "você não vai explicar o enunciado?", "não entendi o que é para fazer" e assim por diante. (SILVA, 2008, p. 54)

O contrato didático existe em função do aprendizado dos alunos e, a cada nova etapa da construção do conhecimento, ele é renovado e renegociado. O professor elabora uma situação didática que fornece condições para o aluno executá-la, sem que o mesmo (professor) faça uma intervenção didática.

Dessa forma, o aluno:

[...] só terá verdadeiramente adquirido [um] conhecimento quando for capaz de aplicá-lo por si próprio às situações com que depara fora do contexto do ensino, e na ausência de qualquer indicação intencional. Tal situação é chamada situação a-didática. (BROUSSEAU, 1996a, p. 38)

Segundo Brousseau, a situação a-didática faz parte de uma situação mais vasta, onde o professor se envolve numa espécie de 'jogo' com as interações dos alunos. Tal 'jogo' evidencia uma situação a-didática pois, sem ter a intenção de atuar didaticamente, ele pode mudar a estratégia do jogador, na busca de um conhecimento específico.

De fato, há uma certa ambiguidade no uso dessa expressão quando ela é compreendida como definindo uma etapa na qual a intenção de ensinar não tem nenhuma influência. Ambiguidade porque ela representa um fenômeno que se encontra fora do controle didático, mas não deixa de ser uma noção de grande importância para a didática.

Segundo Freitas (1999):

As situações a-didáticas representam os momentos mais importantes da aprendizagem, pois o sucesso do aluno nas mesmas significa que ele, por seu próprio mérito, conseguiu sintetizar um conhecimento. Neste sentido não podem ser confundidas com as chamadas situações não didáticas, que são aquelas que não foram planejadas visando uma aprendizagem. Nesse caso o 
problema surge de forma eventual na vivência pessoal do sujeito. (FREITAS, 1999, p. 70)

Concluímos, então, que a escolha do problema pelo professor é uma parte importante de uma situação mais ampla, que é pedagogicamente planejada, e nela pode ocorrer uma ou mais situações a-didáticas. Assim, os sujeitos dos processos de ensino e aprendizagem (professor e aluno) se inserem num conjunto de relações, que envolvem uma diversidade de conceitos, em busca da síntese de um determinado conhecimento. Dessa forma, fica claro que toda a atividade pedagógica deveria ser planejada, pelo professor, com fases bem definidas, com a intenção de direcionar o aluno a uma situação a-didática. Para Pommer (2008),

[...] nas fases da situação a-didática (jogo), o papel do saber é delineado aos poucos, pois na etapa do jogo livre (ação pela ação) praticamente não há saber, pois a estratégia de base prevista é a utilização de uma determinada operação matemática. A busca pelo algoritmo promove uma evolução dos algoritmos locais (formulação) para a estratégia otimizadora (validação) e os objetos de estudo podem ser delineados. (POMMER, 2008, p. 7)

Brousseau afirma que um outro aspecto das situações a-didáticas é a classificação em etapas ou fases: devolução, ação, formulação, validação e institucionalização.

Na primeira fase, denominada situação de devolução, o professor assume a função de ceder ao aluno uma parte da responsabilidade pela aprendizagem, incluindo-o no jogo e assumindo os riscos por tal postura.

$\mathrm{Na}$ segunda fase, denominada situação de ação, o aluno faz reflexões, simulações e tentativas. Nessa etapa o aluno adota um procedimento de resolução, dentro de um esquema de adaptação, através da interação com o jogo, e toma as decisões que faltam para organizar a resolução do problema.

De acordo com Brousseau (1996a), na terceira fase, denominada situação de formulação, ocorre uma troca de informação entre o aluno e o 'milieu', utilizando uma linguagem mais adequada, sem o uso obrigatório da linguagem matemática formal. Desse modo, podem ocorrer: ambiguidades, redundâncias, uso de metáforas, criação de termos semiológicos novos, falta de pertinência e de eficácia de mensagem, dentro de retroações contínuas. Os alunos, então, tentam modificar a linguagem habitual, adequando-a as informações que devem comunicar.

A quarta etapa, situação de validação, é caracterizada pelo momento em que os alunos tentam convencer os interlocutores da veracidade das afirmações, fazendo uso, então, de uma linguagem matemática apropriada, recheada de demonstrações e provas.

Concluímos, então, que nas quatro situações descritas anteriormente, o professor assume o papel de mediador, permitindo que o aluno trilhe os caminhos da descoberta e não revelando sua intenção didática. Essas fases caracterizam passos psicológicos favoráveis ao aluno, pois o engajam na busca do conhecimento, fazendo-o um co-autor do seu processo de aprendizagem,

Por fim, há a situação de institucionalização do saber. Nessa fase, a intenção do professor é revelada e estabelecem-se as convenções sociais. O professor retoma a parte da responsabilidade, outrora cedida aos alunos, e confere o estatuto de saber ou descarta algumas produções dos alunos, definindo os objetos de estudo através da formalização e generalização. 
É na institucionalização que o papel explícito do professor se manifesta, o objeto é oficialmente aprendido pelo aluno e o professor reconhece tal aprendizagem. Brousseau pondera que:

[...] o papel da institucionalização é prover sentido de um conhecimento, que pode ser encontrado pelo próprio aluno nas: - situações de ação: do trama de raciocínios e de de reformulações - situações de formulação: de modelos implícitos associados a ele e das relações mais ou menos assumidas entre estes componentes - situações de validação: do trama de provas e de formalizações situações de institucionalização: onde o saber é identificado, sistematizado e reconhecido. (BROUSSEAU, 1996a, p. 47)

Neste sentido, o professor deve assumir uma epistemologia e ter um bom controle de suas concepções epistemológicas ${ }^{4}$, pois, ao mesmo tempo que ensina um saber, o professor recomenda como usá-lo. Para Brousseau (1996b, p. 59) "manifesta-se assim uma posição epistemológica que o aluno adota muito mais rapidamente porque a mensagem permanece implícita ou ainda inconsciente". Tal posição torna-se difícil de ser assumida, controlada e identificada e, por outro lado, parece desempenhar importante papel na qualidade dos conhecimentos adquiridos.

Para que as situações didáticas sejam planejadas e aplicadas de forma a levar o aluno ao êxito no processo de aprendizagem e ajudar o professor no processo de ensino, entram em cena os materiais de apoio (livros didáticos e os sites disponíveis na internet) e o diálogo.

\section{OS RECURSOS DE ENSINO E DE APRENDIZAGEM}

O livro didático, auxiliar no processo da formação do educando como ser crítico, capaz de criar, construir, descobrir o conhecimento é, sem dúvida, um importante recurso auxiliar nos processos de ensino e aprendizagem.

Polidoro e Stigar (2010) consideram que o papel do livro didático ou da apostila é

[...] propiciar um bom trabalho pedagógico quanto à linguagem científica adequada à faixa etária do educando; às atividades integradas aos conteúdos, para o desenvolvimento de diversas competências; à problematização de questões a estudar e pesquisar, adequadas à capacidade cognitiva dos alunos e aos conceitos a construir, por meio de interlocução, observação, investigação, análise, síntese e avaliação. (POLIDORO \& STIGAR, 2010, p.157)

Entendemos que o livro didático pode ser um dos suportes do processo de aprendizagem e referencial para as atividades extraclasse, tendo um papel significativo na dinâmica escolar. Importante instrumento de reflexão, o livro didático pode ser um elemento facilitador para que professores e alunos argumentem, interajam, participem, contribuam e invistam no desenvolvimento das próprias competências pessoais e profissionais, procurando emancipação

\footnotetext{
${ }^{4}$ Na Didática da Matemática, a concepção epistemológica "é um conjunto de convicções, conhecimentos e saberes científicos, os quais tendem a dizer o que são os conhecimentos dos indivíduos ou de grupos de pessoas, como funcionam, os modos de estabelecer sua validade e então de ensiná-los e aprendê-los" (D'AMORE, 2007, p. 3).
} 
em face da realidade estabelecida e, com isso, construindo um senso crítico a fim de superar a fragmentação do conhecimento e a alienação.

É sabido que, talvez, por conta das necessidades políticas e, principalmente econômicas, muitas vezes o livro didático não consegue ou não cumpre o principal objetivo que é o de possibilitar o acesso à informação de forma clara, concisa e matematicamente correta. Por vezes, encontramos erros de conceito e formalização, que comprometem os processos de ensino e aprendizagem.

De qualquer modo, é certo que as possibilidades de acesso à informação vão além do professor e do livro didático. Atualmente, com o advento da internet, a informação chega aos patamares de ensino de forma rápida e processada. Para Monteiro (2001), "o surgimento da internet e da World Wide Web trouxe novos elementos para o cenário dos meios de comunicação, gerando possibilidades nunca antes imaginadas no sentido da democratização da informação."

Por vezes, a informação que chega via internet deve ser processada, revisada e adequada aos objetivos que se deseja para que se concretizem os processos de ensino e de aprendizagem. Cabe ao professor fazer esse filtro e possibilitar a construção do conhecimento.

Mas, na busca pela construção do conhecimento há, ainda, um fator fundamental para as relações didáticas: o diálogo. As atitudes e procedimentos, baseados no diálogo, são alicerces para os processos de ensino e aprendizagem. Reconhecer os direitos e os respectivos deveres na convivência com o outro, através de discussão oral, é um passo importante para a educação.

Acrescente-se que as situações didáticas são solidificadas a partir do diálogo. Esta relação possibilita, ao aluno, descobrir novos conceitos, desenvolver seu raciocínio e assumir e expressar posicionamentos. O aluno deve assumir-se como corresponsável por sua formação; antes de tudo, deve estar predisposto a aprender para, então, pôr em prática a busca pelo autoconhecimento e pelo desenvolvimento da autoestima, constituindo, assim, sua identidade e autonomia intelectual. É no diálogo que aflora, também, o conflito, ativando, assim, as discussões e a presença participativa dos alunos.

Segundo Monteiro (2001), nas práticas vivenciadas no interior das instituições educativas "ocorre, antes de tudo, um contato humano entre pessoas que pensam e agem e têm, sobretudo, sentimentos. É preciso respeitar o outro no seu modo de ser e, assim, garantir um bom relacionamento, possibilitando um clima de confiança". Para Henández (2002) "o diálogo implica a honestidade e a possibilidade de intervir em um clima de confiança".

É num clima de confiança que os processos de ensino e aprendizagem alcançam a sua plenitude. Quando o aluno confia no professor e o aceita como mediador da construção do conhecimento, mas não detentor do conhecimento e responsável pela transmissão do mesmo, as relações se tornam prazerosas e produtivas.

Entende-se, então, que há um intercâmbio e uma reflexão entre os sujeitos, professor e alunos, que devem estar abertos a novas ideias e formas de pensar, a novas maneiras de 'ver', e não estar fechados em seu próprio ponto de vista. Dessa forma, a aprendizagem é favorecida, a partir do diálogo. Pelo diálogo, as hierarquias são diluídas e os sujeitos se encontram no verdadeiro momento de aprendizagem.

Com relação a isso, Alro e Skovsmose (2006), afirmam que 
[...] um diálogo tem por base o princípio da igualdade. Em um diálogo, não há demonstrações de força e ninguém está querendo vencer. Um participante não pode estar acima do outro. Um diálogo avança em função da pujança da investigação e não é influenciado por considerações acerca, digamos, das consequências de se fazer certas conclusões.[...] Um diálogo não pode ser influenciado pelos papéis (e o poder associado a esses papéis) das pessoas que participam do diálogo. Mas como trazer isso para a sala de aula, onde os processos de ensino e aprendizagem estão visceralmente associados aos papéis de professor e aluno, numa relação desigual? Professor e aluno são posições diferentes, profissionalmente falando; do contrário, não haveria ensino. Contudo, eles podem estar igualitários no nível das relações e comunicações interpessoais. (ALRO e SKOVSMOSE, 2006, p. 131)

Por outro lado, há de se ressaltar que é possível estabelecer relações em que coexistem o diálogo e a autoridade do professor. Tal relação pode ser um complicador na busca da construção do conhecimento.

Nesse sentido, Rego (1996, p. 98) condena o tipo de concepção de autoridade que configura "uma relação professor-aluno baseada no controle excessivo, na ameaça e na punição". Para ele, tal concepção provocará reações diferentes das inspiradas por princípios democráticos.

A forma como o professor demonstra o poder, sendo hábil e utilizando a sua autoridade em sala de aula, contribui para sua eficiência ou para a sua subserviência. Vasconcelos et al (2005) afirmam que

[...] cobrando obediência, impondo suas vontades e seus valores constituir-se-á como autoridade e obterá por parte dos alunos um respeito unilateral, baseado no medo das punições. Já o professor que mantém relações baseadas no respeito mútuo obterá autoridade por competência. (VASCONCELOS et al, 2005, p.5)

Além disso, a prática educativa em que inexiste a relação coerente entre o que o professor diz e o que ele faz, torna-se desastrosa. Pautadas pelas ações que o professor dirige ao aluno e vice-versa, e pelas ideias que um tem do outro, as interações professor-aluno desempenham um importante papel, envolvendo dimensões afetivas e motivacionais que podem contribuir com os processos de ensino e de aprendizagem.

Entende-se, então, que o processo educativo é essencialmente interativo, e a figura do professor é muito importante, pois é ele um dos principais responsáveis por fazer a mediação competente e crítica entre conhecimento e alunos e entre a Educação Matemática e a democracia:

[...] a aprendizagem deve apoiar o desenvolvimento da cidadania, então o diálogo deve ter uma papel preponderante em sala de aula. Dessa forma, uma teoria crítica da aprendizagem incluiria o diálogo com conceito básico. Consideramos que a importância do ensino e da aprendizagem de Matemática dialógicos está associada à relação crítica entre Educação Matemática e democracia. Ensino e aprendizagem dialógicos são importantes para a prática de sala de aula que apoia uma Educação Matemática para a democracia. Consideramos que as qualidades de comunicação, associadas ao diálogo, 
constituem uma fonte de aprendizagem com certas qualidades, a que nós nos referíamos como aprendizagem crítica da Matemática. (ALRO e SKOVSMOSE, 2006, p. 142)

É, principalmente, na sala de aula, que ocorrem relações sociais viabilizadoras do exercício da cidadania. A Educação Matemática tem importante papel no desenvolvimento da capacidade democrática dos cidadãos.

Entendemos, então, que as relações entre professor e aluno devem ser baseadas no diálogo e pautadas na democracia, desenvolvendo a capacidade de interagir em situações sociais e políticas estruturadas pela Matemática. E não só no diálogo entre aluno e professor, mas também entre aluno e aluno. Para Coll e Colomina (1996):

Nos processos de construção de significados compartilhados com relação aos conteúdos escolares, passou-se a considerar a possibilidade de que os próprios alunos podem exercer, em algumas circunstâncias, uma influência educativa sobre os colegas, isto é, podem desempenhar o papel de mediador entre o outro aluno e o saber, o que, antes, era reservado exclusivamente ao professor (COLL e COLOMINA, 1996).

Entendemos que os processos de ensino e aprendizagem são favorecidos tanto pelas interações entre alunos e professor como entre os alunos. A interação entre alunos é particularmente interessante, talvez por estes terem uma linguagem mais adequada aos colegas ou por estarem mais próximos, durante um tempo maior. Desse modo, o diálogo se apresenta de forma mais fluida e o entendimento é facilitado.

Buscando compreender essas diversas interações existentes no ambiente escolar partimos, então, para a observação de alguns encontros em sala de aula.

\section{A OBSERVAÇÃO EM SALA DE AULA}

O trabalho que apresentamos neste artigo é um 'recorte' de uma investigação delineada nos marcos da pesquisa qualitativa que, segundo Lüdke e André (1986), caracteriza-se por:

(i) ter o ambiente natural como sua fonte direta de dados e o pesquisador como seu principal instrumento; (ii) coletar dados predominantemente descritivos; (iii) ter maior atenção ao processo que com o produto; (iv) o processo de análise tende a ser indutivo, sendo que 'os pesquisadores não se preocupam em buscar evidências que comprovem hipóteses definidas antes do início dos estudos. As abstrações formam-se ou se consolidam, basicamente, a partir da inspeção dos dados num processo de baixo para cima. (LÜDKE E ANDRÉ, 1986, p. 10)

Nos meses de maio e junho de 2012 a professora da 1aㅗ série do Ensino Técnico Integrado ao Médio (período vespertino), de um Instituto Federal situado no município de Cubatão-SP, abordou o assunto Trigonometria no triângulo retângulo, seguindo o planejamento escolar. Observamos e gravamos as vozes da professora e dos 37 (trinta e sete) alunos envolvidos, em 03 (três) encontros de 135 (cento e trinta e cinco minutos) cada um, organizados, pelo horário escolar, em aulas triplas. 
O que relatamos e analisamos, a seguir, são alguns 'momentos' de cada encontro. Esses momentos ilustram como as interações saber-professor-aluno aconteceram em sala de aula.

\subsection{Alguns momentos do $1^{\circ}$ encontro}

O primeiro encontro teve como objetivo apresentar a Trigonometria fazendo uma revisitação aos conceitos de Geometria, trabalhados em séries anteriores.

A professora iniciou a aula escrevendo, na lousa, a palavra 'trigonometria' e pediu para que os alunos dessem um significado à mesma. De imediato eles tiveram algumas dúvidas ${ }^{5}$.

Fafá: - Como assim, professora. Tem significado?

Vevê: - Mas, não é o nome da matéria que a senhora vai explicar?

Prof.: - Está bom, vamos lá! Tem significado sim, mas não sou eu que vou dizer. Certo? Vocês, juntos, vão chegar a ele. Ok?

Protocolo 1: primeiro diálogo

Diante dos questionamentos, a professora registrou, na lousa, a palavra dividida em três partes:

\section{Tri / gono / metria}

Figura 2: A separação da palavra trigonometria.

Fonte: Informação coletada pelo pesquisador

E, então, vieram as observações dos alunos e do professor:

Fefê: - Agora ficou fácil. Tri é três, gono vem de ângulo, e metria vem de medida?

Kaká: - Isso mesmo, Fefê. Agora vamos juntar e chegamos a "medida de triângulos". Está certo, professora?

Prof.: - Perfeito, Kaká e Fefê. Viu como foi fácil?

\section{Protocolo 2: segundo diálogo}

O professor proporcionou, naquele momento, que os alunos participassem e tal postura foi de fundamental importância para a condução e favorecimento da comunicação produtiva entre os alunos para que, juntos, trouxessem o significado da palavra em questão. Com a divisão da palavra 'Trigonometria' em três partes, foi possível, aos alunos, buscar os conhecimentos adquiridos anteriormente e chegar ao seu significado. Dessa forma, percebemos que o aluno apropriou-se do saber matemático. O professor, segundo Brousseau (1988), propôs uma situação didática, e o triângulo didático saber-professor-aluno se fez presente. A origem da palavra 'trigonometria', criada pelos cientistas (responsáveis pelo saber científico), a atitude do professor (estratégia didática) em separar a palavra em três partes (saber a ensinar) e a postura dos alunos (fizeram conexões com os conhecimentos anteriores) são a prova de que os saberes geraram um conhecimento.

\footnotetext{
${ }^{5}$ Os nomes dos alunos apresentados, nesse relatório, são fictícios; Prof. se refere à fala da professora.
} 
Aproveitando que os alunos falaram sobre 'triângulos', a professora, igualmente, pediu que eles os definissem. Tal postura evidenciou a posição da professora em relação ao ensino de Trigonometria. Para ela, a Trigonometria tem seus embasamentos na Geometria Plana, conforme já sinalizava Roxo (1937) e indicam as Orientações Curriculares para o Ensino Médio (BRASIL, 2006). Então, a professora incitou os alunos a buscarem conhecimentos anteriores, em Geometria Plana.

Os alunos se entreolharam e disseram que sabiam desenhar, mas não sabiam, exatamente, como definir. Então, professora e Mimi dialogaram:

Prof.: - Não sabem definir? Então vamos fazer juntos. Como devo começar o desenho?

Mimi: - Coloque a caneta na lousa e marque um ponto. Trace uma reta e pare num outro ponto; daí trace outra reta e pare num terceiro ponto. Agora ligue o terceiro ponto ao primeiro, e pronto!

Protocolo 3: terceiro diálogo

A professora foi 'seguindo' as orientações de Mimi e reproduzindo sua fala enquanto fazia a representação na lousa.

Assumir a posição de explicar uma situação ou resolver um problema possibilita, segundo Echeita e Martin (1995), um avanço na aprendizagem, reestruturando o raciocínio e melhorando a compreensão.

Em um determinado momento, Cacá também se posicionou.

Prof.: - Bem, então tá! Estou marcando um ponto; vou denominá-lo ponto A. E agora, do ponto $A$, eu traço um segmento de reta até um outro ponto, o ponto B. A Mimi disse reta. Eu pergunto: é reta? Semireta? Segmento de reta?

Cacá: - É segmento, porque tem começo e fim. A reta é infinita para os dois lados!

Protocolo 4: quarto diálogo

Na fala de Cacá, ficou clara, mais uma vez, a retomada dos conhecimentos de Geometria Plana, adquiridos nas séries anteriores. E a professora, então, seguiu as orientações de Mimi.

Prof.: - Ok! Então saio de A e traço um segmento até um ponto distinto B. Agora eu saio de $B$ e traço outro segmento até um terceiro ponto distinto $C$.

Protocolo 5: quinto diálogo

A professora fez o seguinte traçado na lousa, e os diálogos se seguiram: 


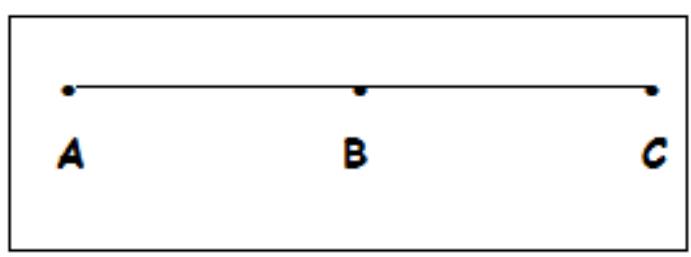

Figura 3: A tentativa de construir um triângulo. Fonte: Informação coletada pelo pesquisador

Prof.: - E agora?

Kaká: - Viu Mimi? Tá tudo errado!

Mimi: - É verdade. Professora, preste atenção. O segundo segmento não pode ser a continuação do primeiro, senão não vai haver triângulo.

Prof.: - Então tem alguma condição para os três pontos?

Cacá: - Tem sim, professora. Os três pontos não podem estar na mesma linha!

Prof.: - Então perfeito. Está feito o desenho e, portanto, definimos um triângulo.

Protocolo 6: sexto diálogo

Mimi não conseguiu explicitar exatamente os procedimentos que lhe vieram à cabeça, com a expressão, para a professora, dos conhecimentos que ela trouxe de outras etapas da sua escolarização. Tal fato originou um erro. O erro, na visão de Brousseau (1996a) e Gálvez (1996) conduz ao acerto, sendo necessário para desencadear o processo de aprendizagem do aluno. A necessidade de externalizar o pensamento ajudou na tomada de consciência de certos erros, corrigindo-os.

\subsection{Alguns momentos do $2^{\circ}$ encontro}

No primeiro encontro, do qual alguns momentos foram relatados anteriormente, a professora passou a aula questionando os alunos sobre os conhecimentos aprendidos nas etapas anteriores de sua escolarização, trazendo à tona alguns conceitos da Geometria Plana. No final do encontro, ao explorar o assunto Triângulos, a professora pediu que eles fizessem uma pesquisa sobre os pontos notáveis (Baricentro, Incentro, Circuncentro e Ortocentro) e sobre as relações entre eles, nos diversos tipos de triângulos (Retângulo, Obtusângulo, Acutângulo, Isósceles, Equilátero e Escaleno).

A professora começou esse segundo encontro, questionando sobre a pesquisa solicitada no encontro anterior e os alunos foram se posicionando: 
Prof.: - Boa tarde pessoal! Na aula passada eu pedi que vocês fizessem uma pesquisa, certo? Fizeram?

Fefê: - Professora, eu pesquisei em sites da internet e até encontrei uma aula pronta sobre os pontos notáveis. Bem legal, né?

Tetê: - Professora, eu consultei os livros didáticos que já havia usado nas séries anteriores. Serve?

Prof.: - Claro que serve. Todos os recursos que vocês usarem para adquirir conhecimento são bem vindos. Mas, vejam bem, a internet tem muita informação não muito confiável, portanto, é prudente consultar várias fontes.

Protocolo 7: sétimo diálogo

Entendemos que, ao consultarem outros materiais de apoio, os alunos cumpriram sua parte no contrato didático, definido por Brousseau (1996a). A pesquisa solicitada pelo professor, e feita através dos livros didáticos e dos sites da internet, possibilitou aos alunos uma revisitação aos conceitos. Os professores precisam, de fato, aceitar essa realidade e ajudar seus alunos a fazer bom uso dela, como fez a professora participante desta pesquisa.

E os diálogos prosseguiram:

Prof.: - Bem, então, vamos ver os resultados. O que é baricentro?

Cacá: - Professora, baricentro é o encontro de três medianas.

Prof.: - Hum...Então, o que é mediana?

Rará: - Mediana é o segmento cujas extremidades são vértices do triângulo.

Prof.: - Como? Segmento cujas extremidades são vértices do triângulo? Vamos tentar representar o que você está falando.

Protocolo 8: oitavo diálogo

A professora, seguindo as orientações de Rará, desenhou um triângulo na lousa:

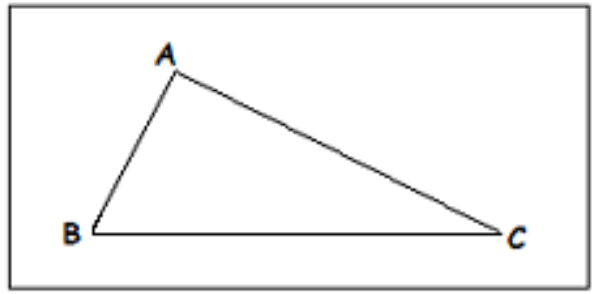

Figura 4: Um triângulo e seus vértices.

Fonte: Informação coletada pelo pesquisador.

Em seguida, ela questionou e Anan respondeu:

Prof.: - Vejam só: se eu ligar os vértices do triângulo eu formo o lado do mesmo, não é? Anan: - Não professora, não é isso. A mediana é o segmento cujas extremidades são um vértice do triângulo e o ponto médio do lado oposto a esse vértice.

Protocolo 9: nono diálogo

Diante do posicionamento de Anan, a professora fez o registro na lousa: 


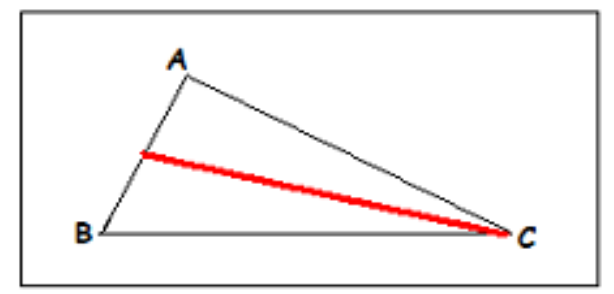

Figura 5: um triângulo e uma de suas medianas.

Fonte: Informação coletada pelo pesquisador.

A professora deu prosseguimento à aula, lançando novas perguntas e os alunos as responderam:

Prof.: - É isso mesmo? A mediana forma ângulo reto com o lado oposto?

Lulu: - Não necessariamente!

Didi: - Depende do triângulo!

Protocolo 10: décimo diálogo

A pergunta foi lançada, as respostas vieram, e a professora não se posicionou sobre o que os alunos disseram. Nos pareceu ser uma estratégia, da professora, para que os alunos refletissem sobre os questionamentos e respostas, sem a sua intervenção.

Imediatamente, lançou outra afirmação, levantou outro questionamento e os posicionamentos continuaram:

Prof.: - O ponto de encontro das medianas é o baricentro. Há alguma propriedade importante com o baricentro?

Anan: - É o centro de gravidade do triângulo!

Rorô: - É o ponto por onde passa a resultante da força peso. O centro de gravidade está no cruzamento dos eixos.

Protocolo 11: décimo primeiro diálogo

Diante das respostas de Anan e Rorô, a professora pontuou:

Prof.: - Bem, em Física, eu preciso muito desse ponto de equilíbrio que é o baricentro.

Protocolo 12: a fala da professora

Aqui percebemos que os alunos foram capazes de se lembrar e relacionar o que estavam aprendendo, com outros conteúdos apresentados em outras disciplinas. De fato, segundo afirmam Assis e Ravanelli (2008), "na Física, o centro de gravidade ou baricentro de um corpo é o ponto onde pode ser considerada a aplicação da força de gravidade de todo o corpo formado por um conjunto de partículas". 


\subsection{Alguns momentos do $3^{\circ}$ encontro}

No segundo encontro, do qual alguns momentos foram relatados anteriormente, a professora retomou conceitos da Geometria Plana, aprendidos pelos alunos nas etapas anteriores e fez uma reformulação de alguns deles, por conta de alguns erros cometidos. No final do encontro, ela introduziu e explicou os conceitos de seno, cosseno e tangente e propôs aos alunos alguns exercícios, que foram discutidos no 3 o encontro.

Trazemos, então, dessa forma, alguns momentos desse encontro.

A professora começou a primeira atividade perguntando aos alunos sobre as dúvidas dos exercícios que foram propostos no encontro passado e se propôs a resolvê-los, no quadro. Os alunos pediram que ela resolvesse alguns exercícios e, então, ela começou, e os questionamentos vieram. Imediatamente, laiá questionou a professora sobre um exercício, iniciando um diálogo:

laiá: - Professora, eu não consegui resolver o exercício 20!

Prof.: - Ok, vamos a ele.

Protocolo 13: décimo segundo diálogo

Reproduzo, então, o enunciado do exercício questionado.

\section{Se tg $a=1 / 3$, calcule sen $a$ (onde $a$ é um ângulo agudo).}

Figura 6: 0 enunciado do exercício 20 do livro didático.

Fonte: Matemática, Contexto e Aplicações (DANTE, 2010, p. 376)

Prof.: - O exercício afirma que a tangente de alfa é $1 / 3$ e ele quer calcular o seno de alfa. Primeiro passo do exercício. Fazer a representação. Como fazê-la?

laiá: - Desenhe um triângulo retângulo e localize um ângulo alfa.

Prof.: - Bem, então vamos lá. O que é tangente de alfa? É o seno de alfa sobre o cosseno de alfa? Se tangente é seno sobre cosseno, então, eu vou colocar o cateto oposto valendo 1 e o adjacente valendo 3. Certo? Vamos usar o Teorema de Pítágoras para encontrar o valor da hipotenusa! Pronto, a hipotenusa é igual a raiz quadrada de 10. Certo? Então o seno de alfa será 1 sobre raiz de 10 . Vamos racionalizar?

Protocolo 14: décimo terceiro diálogo.

Ao afirmar que a tangente é o seno sobre o cosseno e chamar o cateto oposto de 1 e o adjacente de 3 , a professora cometeu um equívoco pois a razão é $1 / 3$ e isto não significa que um cateto vale 1 e o outro vale 3 . Poderiam ser valores proporcionais a 1 e a 3 .

E os diálogos prosseguiram: 
Fefê: - Multiplica em cima e em baixo por raiz de 10 e corta a raiz!

Prof.: - Corta a raiz? Como é isso?

Fefê: - Eu aprendi assim, professora.

Prof.: - Na verdade a raiz não corta nada, o que acontece é que raiz de 10 multiplicada por raiz de 10 é igual a raiz de 100 que vale 10, entenderam?

Fefê: - Ah professora, viu como cortou?

Protocolo 15: décimo quarto diálogo.

Os outros alunos da classe riram copiosamente diante da afirmação. Mas as palavras da aluna expressam um, entre tantos outros erros de conceitos que vêm acompanhando nossos alunos e que podem levá-los a perder o verdadeiro sentido da Matemática.

Num outro momento deste encontro, a professora lançou aos alunos uma proposta de trabalho em que eles se reuniram em duplas, e cada dupla resolveria, em 15 minutos, um determinado exercício e, depois, o registraria no quadro a resolução e explicaria para todos os colegas. Os exercícios estavam, todos, no livro didático.

A professora pediu que as duplas iniciassem o trabalho fazendo a leitura de um exercício proposto e resolvido no livro didático, o que lhes indicaria um caminho para a resolução de outros problemas sobre triângulos retângulos. Trata-se de uma situação a-didática, criada pelo professor, na escolha de problemas que levariam os alunos à construção do conhecimento. Ficou clara, então, a 1a fase dessa situação, denominada 'situação de devolução', preconizada por Brousseau (1996b), em que o professor cede ao aluno uma parte da responsabilidade sobre a aprendizagem.

Esgotado o tempo, a professora chamou a atenção para os processos de resolução de problemas que o livro adota, e pediu que os alunos fossem ao quadro explicar suas resoluções.

Carcar e Cacá foram à lousa, mostrar aos outros colegas e à professora, a forma como resolveram o exercício a eles destinado:

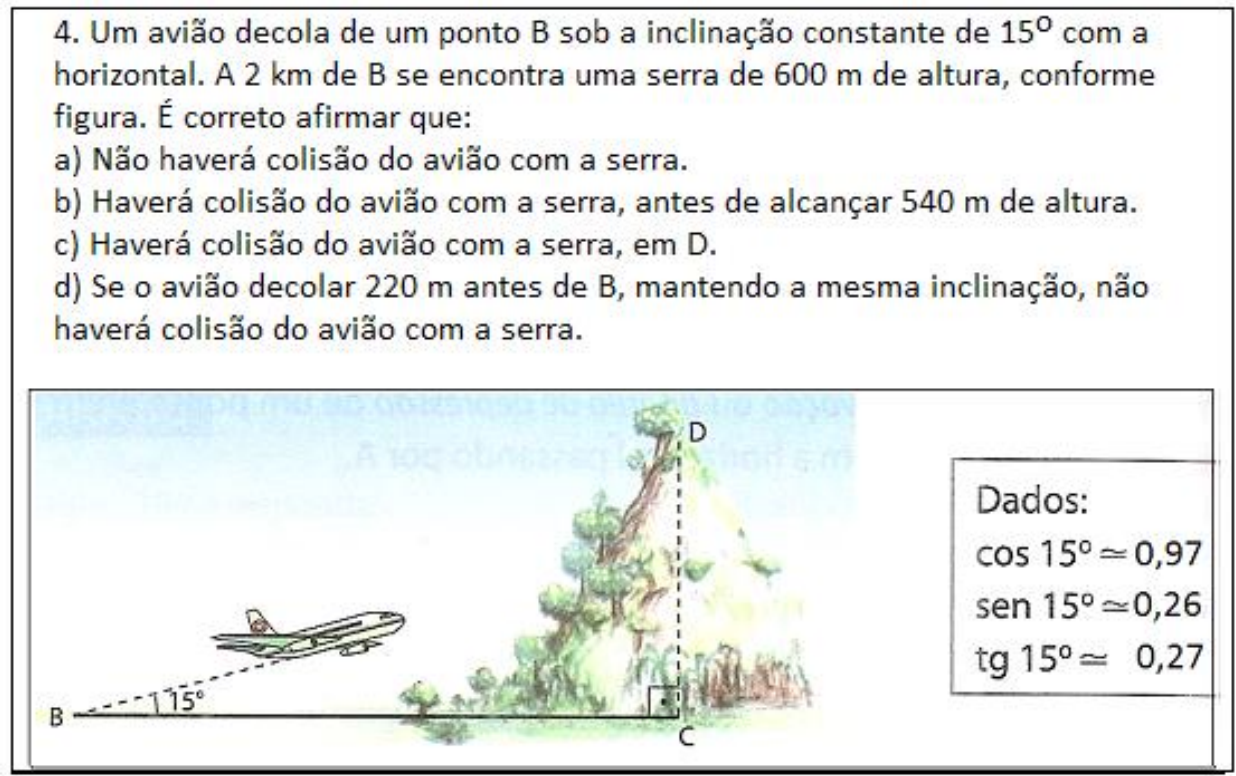

Figura 7: 0 exercício 4 do livro didático.

Fonte Matemática, Contexto e Aplicações (DANTE, 2010, p. 378) 
Carcar - Trata-se de um avião que subirá sob um ângulo de $15^{\circ}$ com a horizontal; há uma distância de $2000 \mathrm{~m}$ de uma serra que tem $600 \mathrm{~m}$ de altura. Na letra (a), a pergunta é: de quanto será o ângulo para o avião não colidir na serra? Na letra (b), ele pergunta qual seria a distância mínima da decolagem para que o avião passasse por cima da serra, numa margem de segurança de $10 \mathrm{~m}$ acima da mesma.

Cacá - Tangente de $15^{\circ}$ é igual a h sobre $2000 \mathrm{~m}$. Como tomamos a tangente de $15^{\circ}$ como 0,27 , então teremos, por regra de três, que $\mathrm{h}=540 \mathrm{~m}$. É a altura em que o avião colidiria com a serra. Na letra (b), devemos considerar a altura da serra de $610 \mathrm{~m}$, por conta da margem de segurança, e aplicar tangente de $15^{\circ}$ igual a 610 sobre $x$, onde $x$ é a distância mínima para a decolagem. Por regra de três teremos que x é aproximadamente $2222 \mathrm{~m}$.

Carcar - Eu fiz por proporção: 2000 m esta para $540 \mathrm{~m}$ assim como x esta para $610 \mathrm{~m}$ e descobri que x é aproximadamente $2222 \mathrm{~m}$. Regra de três simples que dá o resultado e acabou!

Prof.: - E com a mesma distância de 2000 m, qual seria o ângulo para o avião não colidir com a serra?

Cacá - Basta dividir 610 m por 2000 m e, por serem respectivamente os catetos oposto e adjacente, teremos o valor da tangente. Daí é só procurar na tabela!

Protocolo 16: décimo quinto diálogo

A resolução de um problema matemático pode levar o aluno a refletir sobre tal, mesmo que, às vezes, de forma superficial e fragmentária. Essa reflexão, muitas vezes, não é explicitada e o próprio aluno não toma consciência sobre o que está pensando; esta é a segunda fase denominada 'situação de ação'. No entanto, durante a interação, ele precisa explicitar suas ideias e suas hipóteses para que o colega tome conhecimento delas e eles possam, assim, compartilhar esse pensamento de forma que ambos construam a solução. Trata-se da 3 a fase, 'situação de formulação', onde podem aparecer metáforas, criação de termos semiológicos novos, falta de pertinência e de eficácia de mensagem, dentro de retroações contínuas. Tal situação se confirmou quando os alunos, efetivamente, mostraram, aos outros, a forma como resolveram o problema. Percebemos que o professor não institucionalizou o saber de forma explícita, mas ao aceitar a resolução proposta pelos alunos como correta, tal institucionalização se fez presente.

A professora percebeu que alguns alunos não estavam envolvidos com a explicação de Carcar e Cacá. Como observadores também percebemos tal fato, e a nós, pareceu que a pressão de apresentar a resolução do exercício, no quadro, fez com que os alunos que deveriam estar ouvindo os colegas, focassem apenas no que Ihes foi pedido e não se preocupassem com o desenrolar da aula e com os exercícios explicados e resolvidos pelas outras duplas. Por isso a professora fez um comentário: 


\begin{abstract}
Prof.: - Eu pedi uma tarefa que era fazer a leitura da página 378 do livro didático, onde ele explicava como se resolve o problema. Alguns aqui, passaram "batido". [...] ler não é simplesmente juntar letrinhas e formar palavrinhas e dizer que leu. Tem que entender o que leu! E na interpretação ele dizia que pra resolver um problema eu preciso ler com atenção, tirar os dados do problema, arrumar uma estratégia para resolver o problema e 'botar' em prática a estratégia que eu pensei. Tem gente que está perdida, que não tem estratégia, que não sabe nem representar o problema. Então, em primeiro lugar precisar aprender a ler. Nós fizemos pelo menos uns 10 problemas na lousa e eu percebo que muitos estão mais interessados em "bater-papo" do que entender o problema. Eu quero ver como será na hora da avaliação do bimestre!
\end{abstract}

Protocolo 17: a fala da professora

Diante disso, os alunos se entreolharam assustados, mas nada falaram.

\title{
4.4 Fim do encontro.
}

Parece ter ficado claro, nesse momento, a quebra do contrato didático anunciado por Brousseau (1996a), quando os alunos não se comportaram conforme era esperado pelo professor. Na verdade, a quebra pode, às vezes, alavancar o processo de aprendizagem. Entretanto, não foi o que aconteceu neste instante.

Ressalte-se ainda, que a fala da professora sinalizou para os alunos, nesse momento, um tipo de ameaça ou punição, condenado por Rego (1996). Pensamos que se, na estratégia didática, fosse dado um maior tempo para que os alunos resolvessem seus exercícios em duplas, e ao final fosse cobrado que todas as duplas participassem ativamente das explicações, a participação teria sido mais efetiva e produtiva e, talvez, a quebra do contrato não tivesse ocorrido.

\section{CONSIDERAÇÕES FINAIS}

Ao finalizar, queremos destacar que, nessa prática de ensino com a Trigonometria no triângulo retângulo, a Teoria das Situações Didáticas (TSD) explicou e ajudou a analisar como as interações entre aluno, professor e saber, auxiliaram na construção do conhecimento, objetivo do presente artigo.

Pela TSD, percebemos que uma prática de ensino atinge seu objetivo quando os alunos envolvem-se ativamente nas discussões mediadas pelo professor. Em todo o percurso da aula, os alunos foram se posicionando, relatando o que trouxeram de outros anos escolares e construindo, em conjunto, um conhecimento.

Pensamos que ao se dar voz aos alunos, a professora tornou possível encontrar posicionamentos interessantes e concisos, refletir e reconstruir conhecimentos. Nos momentos dos encontros apresentados neste artigo, o diálogo foi uma forma importante e eficaz para a construção do conhecimento, e a interação professor-aluno se reforçou pela ideia de que ambos 
podem construir amplas parcelas de significados compartilhados sobre os conteúdos de ensino e que os alunos, uns aos outros, podem, também, auxiliar-se nessa construção.

Algumas reflexões de caráter mais específico também são relevantes: merece destaque a criatividade manifestada pelos alunos e os conhecimentos que demonstram nas respostas rápidas e espontâneas.

Em alguns momentos da aula a institucionalização dos conceitos matemáticos poderia ter sido mais explícita e reforçada, deixando os alunos mais seguros e sendo um momento propício para agregar, aos conhecimentos anteriores, novos saberes, apropriar-se da linguagem matemática e construindo novos conhecimentos.

Portanto, acreditamos que a aprendizagem de um conteúdo ou a resolução de um problema, conjuntamente, onde os alunos tenham a oportunidade de explicitar o seu conhecimento e confrontar o seu ponto de vista com o de outros colegas, pode ser uma situação favorável para que os participantes ajudem-se mutuamente, no sentido de superarem as dificuldades que encontram ou os erros que cometem durante a realização da tarefa.

Muitas vezes a interação social dificilmente ocorre na sala de aula e perde-se bastante do que poderia ser aproveitado a partir das discussões e trocas que os alunos são capazes de fazer quando são estimulados. Sabe-se que a interação não é uma prática que se adquire em um único momento, mas uma prática que precisa ser construída no dia-a-dia. Professor e aluno são responsáveis, então, por estimular essas interações, contribuindo assim para que os processos de ensino e aprendizagem atinjam seus objetivos.

\section{REFERÊNCIAS BIBLIOGRÁFICAS}

1. ASSIS, A. K. T.; RAVANELLI, F. M. M. Reflexões sobre o conceito de centro de gravidade nos livros didáticos. Ciência \& Ensino, vol. 2, n. 2, junho de 2008. Disponível em http://prc.ifsp.edu.br/ojs/index.php/cienciaeensino/article/download/183/139 Acesso em: 15 ago. 2013.

2. ALMOULOUD, S. A. As transformações do saber científico ao saber ensinado: o caso do logaritmo. Educar em Revista, Curitiba, Brasil, n. Especial 1/2011, p. 191-210, 2011. Editora UFPR. Disponível em http://www.scielo.br/pdf/er/nse1/13.pdf Acesso em: 18 jul. 2013.

3. ALRO, H.; SKOVSMOSE, O. Diálogo e Aprendizagem em Educação Matemática. Belo Horizonte: Autêntica, 2006.

4. BELO, J. L. P. Metodologia Científica. Rio de Janeiro, 2004. Disponível em http://www.pedagogiaemfoco.pro.br/met01.htm Acesso em: 24 abr. 2013.

5. BRASIL. Ministério da Educação e Cultura. Orientações Curriculares para o Ensino Médio (2006). Disponível em http://portal.mec.gov.br/seb/arquivos/pdf/book_volume_02_ internet.pdf Acesso em: 18 abr. 2013.

6. _. Parâmetros Curriculares Nacionais (2000). Disponível em http://portal.mec.gov. br/seb/arquivos/pdf/livro01.pdf Acesso em: 18 abr. 2013.

7. BROUSSEAU, G. Fundamentos e Métodos da Didáctica da Matemática. In: BRUN, J. Didática das Matemáticas. [Trad: FIGUEIREDO, M. J.] Lisboa: Instituto Piaget, 1996a. Cap. 1. p. 35-113.

8. _L_ Le contrat didactique: le milieu. Reserches em Didactiques des Mathématiques, v.9, 
n.3, p. 309-336, Grenoble, 1988.

9. __ Os diferentes papéis do professor. In: PARRA, Cecília; SAIZ, Irma (org). Didática da Matemática: Reflexões Psicológicas. Porto Alegre: Artes Médicas, 1996b. Cap. 4. p. 48-72.

10. CHAVES, M. I. J. Modelagem Matemática e Contrato Didático: Impressões de uma experiência. Universidade Federal do Pará- UFPA, Pará, 2013. Disponível em http://www.ufpa.br/npadc/gemm/documentos/docs/mmcd.pdf Acesso em: 26 abr. 2013.

11. CHEVALLARD, Y. La Transposition Didactique: du savoir savant au savoir enseigné. Grenoble: La Pensée Sauvage, 1991.

12. COLL C.; COLOMINA, R. Interação entre alunos e aprendizagem escolar. In.: Coll, Palacios e Marchesi, Desenvolvimento psicológico e educação, v. II, Porto Alegre : Artes Médicas, 1996.

13. D'AMORE, B. Epistemologia, Didática da Matemática e Práticas de Ensino. In: Bolema, v. 20, n. 28, 2007. Disponível em http://www.dm.unibo.it/rsddm/it/articoli/damore/635\%20\%20 Epistemologia\%20Didattica.pdf Acesso em: 10 jan. 2013.

14. DANTE, L. R. Matemática: Contexto e Aplicações. São Paulo: Ática, 2010.

15. ECHEITA, G.; MARTíN, E. Interação social e aprendizagem. In.: Coll, Palacios e Marchesi, Desenvolvimento psicológico e educação, v. III, Porto Alegre : Artes Médicas, 1995.

16. FREITAS, J. L. M. Situações Didáticas. In: MACHADO, Silvia Dias Alcântara (org.) Educação Matemática Uma introdução. São Paulo: Educ, 1999. p. 65-87.

17. GÁlVEZ, G. A Didática da Matemática. IN.: Parra, C. \& Saiz, I (orgs.) Didática da Matemática: Reflexões Psicopedagógicas. Porto Alegre: Artes Médicas, 1996.

18. HENÁNDEZ, F. O diálogo como mediador da aprendizagem e da construção do sujeito na sala de aula. Revista Pátio, Ano VI n. 22 jul/ago, 2002

19. LÜDKE, M; ANDRÉ, M. E. D. A. Pesquisa em educação: abordagens qualitativas. São Paulo: EPU, 1986. p. 9.

20. MENEZES, M. B.; LeSSA, M. M. L.; MENEZES, A. P. A. B. A Emergência de Fenômenos Didáticos em Sala de Aula: a Negociação de uma Sequência Didática em Álgebra Inicial. 2006. Disponível em http://www.sbem.com.br/files/ix_enem/Html/comunicacaoCientifica.html Acesso em: 17 jul. 2013.

21. MONTEIRO, L. A internet como meio de comunicação: possibilidades e limitações. INTERCOM - Sociedade Brasileira de Estudos Interdisciplinares da Comunicação XXIV Congresso Brasileiro da Comunicação - Campo Grande /MS - setembro 2001. Disponível em http://www.portalrp.com.br/bibliotecavirtual/comunicacaovirtual/0158.pdf Acesso em: 25 abr. 2013.

22. PAIS, L. C. Transposição didática. In: MACHADO, Silva Dias Alcântara (org). Educação Matemática Uma (nova) introdução. São Paulo: Educ, 2008. p. 11-48.

23. POLIDORO, L. F.; STIGAR, R. A transposição didática: a passagem do saber científico para o saber escolar. Ciberteologia, Revista de Teologia \& Cultura, 2010. Ano VI, n.27, p.153-159. Disponível em http://ciberteologia.paulinas.org.br/ciberteologia/wp-content/uploads/2009/ 12/02A-transposicao-didatica.pdf Acesso em: 25 abr. 2013.

24. POMMER, W. M. Brousseau e a idéia de Situação Didática. In: SEMA - Seminários de Ensino de Matemática. São Paulo, FEUSP, 2008. 
25. REGO, T. C. R. A indisciplina e o processo educativo: uma análise na perspectiva vygotskyana. In: J. R. G. Aquino (Org.) Indisciplina na Escola: alternativas teóricas e práticas. São Paulo: Summus editorial, 1996.

26. ROXO, E. A Matemática na Educação Secundária. São Paulo: Companhia EditoraNacional, 1937.

27. SILVA, B. A. Contrato Didático. In: MACHADO, Silva Dias Alcântara (org). Educação Matemática Uma (nova) introdução. São Paulo: Educ, 2008. p. 50-75.

28. VASCONSCELOS, A. A.; SILVA, A. C. G.; MARTINS, J. S.; SOARES, L. J. A presença do diálogo na relação professor-aluno. In: V Colóquio Internacional Paulo Freire - Recife, PE. 2005. 